\title{
IMAGEM DA EDITORA UFSM: SOB A PERCEPÇÃO DOS AUTORES DOCENTES
}

\author{
CERETTA, Shani Carvalho ${ }^{1}$ \\ TREVISAN, Laís Viera ${ }^{1}$ \\ CORONEL, Daniel Arruda ${ }^{2}$ \\ OLIVEIRA, Marta Olivia Rovedder de $\mathrm{e}^{3}$ \\ GROHMANN, Márcia Zampieri ${ }^{4}$
}

\begin{abstract}
RESUMO: Compreende-se imagem como um conjunto de opiniões e representações sobre determinada organização, serviço, marca ou produto. No campo das organizações públicas, tal assunto ainda precisa ser mais explorado, portanto, este estudo visa identificar como se configura a imagem da Editora da UFSM na percepção dos autores docentes vinculados à instituição. Metodologicamente, utilizou-se o Método de Configuração de Imagem, desenvolvido e validado por Schuler e De Toni (2015), em pesquisa de natureza exploratória descritiva, com abordagem qualitativa, realizada via entrevistas semiestruturadas. Os resultados abarcam a caracterização dos respondentes, a identificação dos atributos da imagem da Editora UFSM, a delimitação das zonas e dimensões da imagem. Ainda, evidenciou-se que a Editora UFSM assume uma imagem positiva dentre os pesquisados, porém, questões pontuais merecem serem revistas pela gestão para que atendam melhor às expectativas dos autores.
\end{abstract}

Palavras-chave: Configuração de imagens. Editora universitária. Serviço público.

SUMMARY: We comprehend image as a set of opinions and representations about determined organization, service, brand or product. In the field of public organizations, such issue still needs be explored; therefore, this study seeks to identify how the image of UFSM publishing house is configured in the perception of the authors-professors linked to such institution. Methodologically, we used the Method of Image configuration, developed and validated by Schuler and De Toni (2015), in research of descriptive exploratory nature, with qualitative approach, carried out via semi-structured interviews. The results encompass the characterization of the respondents, identification of the image attributes of UFSM Publishing House, delimitation of the zones and dimensions of image. Also, it was evinced that UFSM Publishing House assumes a positive image among the ones that were researched, however, punctual questions deserve to be reviewed by the management to better meet the expectations of the authors.

Keywords: Image configuration. University Publishing House. Public Service.

\section{INTRODUÇÃO}

O estudo acerca da imagem das organizações tem papel fundamental na compreensão da maneira como os clientes as percebem, de forma que possam seguir atuando nas proposições que possuam um feedback positivo e possam intervir nas necessidades de melhorias. Conforme De Toni (2005, p. 55),

\footnotetext{
${ }^{1}$ Mestranda do Programa de Pós-Graduação em Gestão de Organizações Públicas (PPGOP) da Universidade Federal de Santa Maria (UFSM). Assistente em Administração - UFSM. E-mail: laisvtrevisan@ gmail.com.

${ }^{2}$ Professor Associado do Departamento de Economia e Relações Internacionais, com atuação como Docente Permanente nos Programas de Pós-Graduação (Stricto sensu) em Gestão de Organizações Públicas, de Agronegócios e de Economia e Desenvolvimento, da Universidade Federal de Santa Maria (UFSM). Atualmente, é bolsista de produtividade do Conselho Nacional de Desenvolvimento Científico e Tecnológico (CNPq), diretor da Editora UFSM e presidente do seu conselho editorialE-mail: daniel.coronel@uol.com.br

${ }^{3}$ Doutora em Administração pela Universidade Federal do Rio Grande do Sul (UFRGS). Professora adjunta da Universidade Federal de Santa Maria (UFSM). E-mail: mrovedder@gmail.com

${ }^{4}$ Doutora em Engenharia de Produção e Sistemas pela Universidade Federal de Santa Catarina (UFSC). Professora Associada IV da Universidade Federal de Santa Maria. E-mail: marciazg@gmail.com
} 
“imagens são representações, impressões, convicções e redes de significados de um objeto (produto, marca ou organização) armazenadas na memória de forma holística". No âmbito da imagem pública, pode ser compreendida como "um conjunto multifacetado, dinâmico e um tanto volátil de fluxos de informação, opiniões e representações mentais e/ou articuladas" aplicáveis às organizações do Estado, do mercado e da sociedade, a grupos sociais e aos cidadãos individualmente (NOLETO FILHO, 2014, p. 12). Neste sentido, a imagem pública significa as imagens conceituais coletivas circulantes na sociedade, na mídia, na cultura política que faz referência à reputação, ao caráter, à competência, ao prestígio social de pessoas e instituições, bem como à confiança a elas atribuída.

Sob esta perspectiva, poucos estudos acadêmicos voltaram a compreender como se constrói a imagem de organizações, órgãos e políticas públicas sob o ponto de vista dos cidadãos usuários. Dentre as pesquisas realizadas, evidencia-se uma desenvolvida por pesquisadores da Universidade de Brasília, a qual buscou identificar as percepções sobre o Programa Bolsa Família na sociedade brasileira (CASTRO et al., 2009) e evidenciou o nível de legitimidade política, importância e aumento do apoio popular do PBF junto à sociedade. À partir do estado da arte realizado, não foram evidenciados quaisquer estudos a respeito da imagem de instituições de ensino e seus órgãos internos. A maioria das pesquisas de cunho semelhante é voltada a compreender a satisfação ou qualidade percebida pelos usuários dos serviços. Portanto, o objetivo deste estudo consiste em identificar como se configura a imagem da Editora da Universidade Federal de Santa Maria (UFSM) na percepção do segmento dos autores docentes vinculados à instituição. Como objetivos específicos, foram estabelecidos: a) identificar os atributos da imagem relacionada à Editora UFSM na percepção dos autores docentes vinculados à UFSM; b) analisar a composição da imagem no que se refere ao seu conjunto de dimensões afetiva, emocional, racional e visionária; e c) identificar pontos de melhoria para a Editora.

Do ponto de vista prático, o presente trabalho é relevante para a Editora, pois coloca em evidência um conjunto de elementos que configuram a imagem da organização, de forma estruturada, servindo como fonte de informações para políticas estratégicas futuras a serem definidas pela administração, corroborando com a formação de diferenciais competitivos, já que os resultados poderão identificar necessidades de melhorias nas diversas áreas da Editora, de forma a poder entregar melhores serviços aos seus clientes, alinhados aos objetivos estratégicos.

Este trabalho foi estruturado em quatro seções. A primeira contém as considerações iniciais do estudo; a segunda apresenta o referencial teórico; a terceira seção traz o método adotado para o estudo; a quarta apresenta a análise e interpretação dos resultados obtidos na pesquisa; e, a última, as considerações finais da pesquisa.

\section{CONCEITOS DE IMAGEM}

Uma das primeiras concepções a respeito da imagem foi elaborada por Platão, a qual enfocava o caráter de imagem como processo de representação (JOLY, 2012). Já em uma perspectiva voltada ao marketing, Kotler e Keller (2006) compreendem imagem como a forma como os públicos percebem a empresa ou os produtos ofertados por ela e as percepções, crenças e associações retidas pelos consumidores caracterizam a imagem que eles têm sobre uma determinada marca. Ainda, para De Toni et al. (2011, p. 93), "a imagem é um todo invisível, que reúne diferentes elementos sensoriais, emocionais, cognitivos e simbólicos, e seu entendimento se dá pela compreensão dos distintos componentes que a formam, os atributos da imagem".

Conforme Vaz (1995), o conceito de imagem se popularizou nas ciências das comunicações humanas a partir da década de 1950 e caracteriza-se como as ideias que as pessoas assimilam e que tornam 
conscientes sobre determinado objeto, fato, pessoa ou instituição. Ademais, complementa que o marketing utiliza a imagem para caracterizar o quadro de referências que os consumidores/clientes estabelecem sobre quais ideias merecem seu interesse, simpatia e apoio. Essas concepções são confrontadas às experiências individuais de cada pessoa e, logo, assumem distintas percepções e valores.

Portanto, pode-se dividir a imagem em dois domínios: imagem enquanto representação visual (signos); e as imagens subjetivas ou mentais. Ainda que cada um com suas particularidades, Santaella e Nöth (2001) afirmam que ambos os domínios não existem separadamente, pois são extremamente conectados. Para realização deste estudo foram abordadas as imagens de domínio subjetivo, a partir de três perspectivas de imagens: das representações mentais; das representações sociais; e da perspectiva do marketing. Schuler e De Toni (2015) ressaltam como elemento característico dos modelos mentais a inferência. Esta é uma operação mental fundamental para construção de modelos e para o raciocínio humano, pois coloca o fenômeno observado em paralelo a outro já conhecido para facilitar sua compreensão. Cabe ressaltar que os modelos mentais são dinâmicos e em constante aprimoramento, conforme as vivências de cada indivíduo e as situações impostas pelo ambiente (CHAPMAN; FERFOLJA, 2001).

Farr (1995) cita Durkheim quando infere que o estudo das representações individuais é do campo da Psicologia, enquanto as representações coletivas incumbem à Sociologia. Baseado nisso, o psicólogo social francês Serge Moscovici propõe a Teoria das Representações Sociais, na qual advoga que estas fazem parte, "tanto na medida em que ela possui uma contextura psicológica autônoma como na medida em que é própria de nossa sociedade e de nossa cultura" (MOSCOVICI, 1978, p. 45). Neste sentido, relaciona sujeito e objeto para o processo de construção do conhecimento, que é, concomitantemente, individual e coletivo. Portanto, as representações sociais são ancoradas em duas funções que permitem com que as ideias, práticas e valores sejam amplamente enraizados em uma cultura. Na primeira, os indivíduos conhecem e se apropriam destes de modo a garantir uma ordem de convivência no mundo material e social. Já a segunda função serve como um código de trocas sociais entre membros de uma comunidade (JOVCHELOVITCH, 1998).

As teorias a respeito das imagens sob uma perspectiva do marketing e sobre o processo de formação das imagens não possuem um único conceito na academia, sendo discutidas de formas distintas por Reynolds e Gutman (1984), Barich e Kotler (1991) e Stern, Zinkhan e Jaju (2001). Aqui será apresentada a proposta de Barich e Kotler (1991), os quais propõem quatro perspectivas de imagem sob o aspecto do marketing: (i) a do produto - como os consumidores o veem; (ii) a da marca - e sua comparação com as concorrentes; (iii) a do marketing - mix de marketing e qualidade da oferta; e (iv) a da imagem corporativa - a empresa na sua totalidade.

\subsection{Modelos de mensuração de imagem}

A literatura vigente propõe vários modelos de mensuração de imagem de marca e de organizações, dada a importância do tema como instrumento de competitividade no mercado, como os propostos por Fox e Kotler (1994) e Borges-Andrade e Pilati (2000). Trata-se de uma temática relevante, pois propõe um aprofundamento, sob a perspectiva dos clientes da organização, servindo de base para identificação das potencialidades, fraquezas, oportunidades e ameaças. A opção pelo Método de Configuração de Imagem (MCI) se justifica, pois este modelo é o que melhor serve aos objetivos desta pesquisa, tendo em vista que é facilmente adaptável a qualquer organização, seja ela de produtos ou serviços, pode ser realizado de modo qualitativo, sem a presença de muitos participantes e oferece um panorama total do objeto de análise. O MCI foi elaborado por Schuler e De Toni (2015) e é constituído por dimensões que perpassam 
os mapas de natureza física e material (sensorial); emocional; mental (racional); afetiva; simbólica (expressiva); visionária; e axiomática (referente a propósitos e princípios). Para este estudo, apenas as categorias afetiva, emocional, racional e visionária serão conceituadas, pois se optou por utilizar somente estas no desenvolvimento da pesquisa. As demais foram excluídas por não se adaptarem à organização ou por se mostrarem pouco significativas durante o teste piloto, conforme as delimitações traçadas adiante, na seção destinada ao método.

Assim, a percepção de nível emocional pressupõe os julgamentos e avaliações as quais o indivíduo faz sobre o objeto, tanto em relação ao seu interesse com ele, à utilidade e benignidade percebida. A partir disso, obtêm-se informações de "caráter qualitativo, avaliativo, despertando humores, interesses ou afetos" (SCHULER; DE TONI, 2015, p. 24). Estes atributos vão compor uma parte importante da imagem da organização, a qual influenciará futuras relações a serem estabelecidas entre as partes (MARTINEZ; CHERNATONY, 2004). Na percepção de nível racional, Schuler e De Toni (2015) entendem que, a partir da tomada de consciência sobre um objeto, busca-se a compreensão e a profundidade de seu conteúdo. Portanto, essa ponderação racional influencia naquilo primeiramente observado, evidenciando as qualidades percebidas de maneira pragmática, funcional e lógica.

O nível de percepção afetivo pode ser compreendido como a soma obtida a partir dos níveis anteriores, pois estes criarão uma impressão de afetividade sobre o objeto para o indivíduo. Schuler e De Toni (2015) afirmam que percepções afetivas positivas geram um desejo de cuidado e cultivo do objeto; enquanto negativas incorrem em impulsos de aniquilação e impedimento. Por fim, o nível de percepção visionário compreende aquilo que desejamos introduzir de mudanças ao que temos de experiência com o objeto, trazendo uma nova forma de integração do percebido, a partir do que desejamos, tememos ou decidimos. É o que Kotler e Keller (2006) consideram como o "produto esperado", o qual vai além do que o consumidor vê, testa e adquire, mas expressa o que ele almeja a respeito do produto ou serviço. Trata-se de uma dimensão importante da imagem, pois permite que as organizações visualizem o que é desejado e utilizem como parâmetros para introduzir melhorias nas suas ofertas, acompanhando as tendências. A seção seguinte apresentará o método utilizado neste estudo para delinear a pesquisa.

\section{MÉTODO}

Para obtenção dos objetivos deste estudo, fez-se necessária realização de uma pesquisa de natureza exploratória descritiva, com abordagem qualitativa. Como instrumento de pesquisa foi utilizado o Método de Configuração de Imagem (MCI), proposto por Schuler e De Toni (2015). Tal instrumento foi testado e validado na identificação de imagens de organizações, produtos, marcas e serviços pela tese de doutorado desenvolvida por De Toni, em 2005.

O desenvolvimento do MCI é composto por três fases: a) configuração do conteúdo das entrevistas: compreende seleção da amostra, pré-teste, identificação dos atributos salientes da imagem, classificação dos atributos em cada categoria e atribuição dos valores de ordem e de frequência; b) configuração de agrupamentos: refere-se à configuração de agrupamentos, no qual se encontra mensuração do grau de importância dos atributos, verificação do agrupamento dos atributos em fatores de importância e verificação do agrupamento dos atributos em fatores de satisfação; e c) relatório de resultados. Na sequência, será apresentada a organização objeto de análise do presente estudo.

\subsection{Descrição da análise de estudo}

A Editora da UFSM foi criada em 1981 e trata-se de um Órgão Suplementar Central, diretamente 
subordinada ao Gabinete do Reitor, com autonomia administrativa, financeira e editorial. Tem como finalidade implementar e executar a política editorial da unidade. Especificamente, objetiva incentivar a produção científica, literária, tecnológica, didática e cultural da UFSM, da sua região de influência e do país; editar, coeditar e divulgar os trabalhos que interessem às atividades de ensino, pesquisa e extensão nas diversas áreas do conhecimento; promover o intercâmbio bibliográfico com outras unidades, bibliotecas e entidades similares; e manter postos de venda, permanentes e ocasionais, com a finalidade de facilitar à comunidade acadêmica e aos demais interessados o acesso ao material publicado.

Atualmente, a estrutura organizacional é formada por onze servidores e em seu acervo constam 185 títulos diferentes disponíveis no catálogo, nas versões impressas e digitais, e mais de 350 títulos publicados ao longo de sua trajetória; ademais, adiciona ao catálogo, em média, 18 títulos anualmente. No último exercício, 2018, 26 obras originais foram encaminhadas ao Conselho Editorial da Editora UFSM, das quais somente sete foram aprovadas para publicação e seis encontram-se em processo. Na sequência, será identificado o modo de seleção da população e os sujeitos da pesquisa.

\subsection{Seleção da população e sujeitos, técnica de coleta de dados e análise dos dados}

Para a seleção da população e sujeitos, utilizaram-se alguns critérios. Inicialmente, delimitaram-se os autores docentes vinculados à UFSM, tendo em vista que compõem o maior percentual (65\%) de autores que submetem obras para o Conselho Editorial da Editora UFSM, conforme dados de registro do setor, de 2014 a 2018. A partir disso, restringiu-se aos autores que possuem obras em constância no catálogo da Editora UFSM, tendo em vista que estes ainda possuem vínculo com o órgão. Assim, os sujeitos da pesquisa entrevistados foram selecionados de modo estratificado entre os autores e, posteriormente, de forma aleatória simples, com auxílio de planilha Excel. A quantidade adotada foi estabelecida pelo critério de saturação teórica, a qual foi satisfeita com a décima entrevista.

Como técnicas de coleta de dados, foram utilizadas a revisão bibliográfica e a entrevista semiestruturada. Deste modo, este estudo partiu de uma revisão bibliográfica acerca dos temas imagens e suas diferentes representações e as dimensões de imagens elencadas por Schuler e De Toni (2015). Na sequência, foram realizadas entrevistas semiestruturadas individuais para identificar como os entrevistados configuram a imagem da Editora UFSM. As entrevistas foram realizadas pessoalmente e de forma gravada. O roteiro das entrevistas foi baseado e adaptado a partir do modelo proposto por Schuler e De Toni (2015). O modelo é caracterizado como qualitativo no tratamento das respostas e quantitativo devido à soma dos resultados, por análise das entrevistas. $\mathrm{O}$ instrumento é composto por sete questões que têm o intuito de evocação livre de atributos sugeridos pelo modelo MCI. O Quadro 1 apresenta o roteiro da entrevista.

Quadro 1 - Roteiro de questões da entrevista e respectivas dimensões de imagem.

\begin{tabular}{|l|l|}
\hline \multicolumn{1}{|c|}{ Questões } & \multicolumn{1}{c|}{ Dimensões } \\
\hline $\begin{array}{l}\text { Quando eu digo Editora UFSM, qual a primeira coisa que lhe vem à mente? } \\
\text { Que outras ideias lhe vêm à mente sobre a Editora UFSM? }\end{array}$ & Atributos top of mind \\
\hline Quais sentimentos lhe vêm à mente sobre Editora UFSM? & Afetiva \\
\hline $\begin{array}{l}\text { Do que você gosta na Editora UFSM? } \\
\text { Do que você menos gosta na Editora UFSM ou considera como pontos a serem } \\
\text { melhorados? }\end{array}$ & Emocional \\
\hline Em que termos você considera a Editora UFSM útil? & Racional \\
\hline O que você espera da Editora UFSM, no futuro? & Visionária \\
\hline
\end{tabular}

Fonte: Adaptado de Schuler e De Toni (2015). 
As questões top of mind da entrevista contribuem para a identificação indiscriminada dos atributos gerais que permeiam a memória dos sujeitos, a partir da menção do nome da organização e podem ser considerados os que mais se relacionam à marca. Conforme Schuler e De Toni (2015), o modo MCI compreende estas repostas como Valores de Ordem (VO), aos quais serão atribuídos pesos de 5 a 1 (sendo o primeiro atributo valendo 5 e o quinto, se houver, valendo 1 , por ordem de evocação do entrevistado; os demais valerão 0 ).

Como procedimento de conferência e validação, foi implementado um pré-teste ou teste piloto com professores experientes em publicação de livros, o qual consistiu na aplicação do roteiro de entrevista para uma amostra de duas pessoas, visando corrigir falhas no instrumento de coleta de dados e verificar o seu tempo de aplicação.

Como técnicas de análise de dados, o primeiro procedimento trata-se da análise do conteúdo dos registros das entrevistas, as quais se deram mediante gravação e, posteriormente, transcrição. A segunda fase é caracterizada pela configuração de conteúdo, na qual acontece a classificação dos atributos identificados em suas categorias a partir dos seus sinalizadores, atribuindo, a cada um, sua respectiva dimensão predefinida: afetiva (reconhecimento, respeito e valorização), emocional (apreciação, ataque, fuga, medo, percepção de características de masculinidade ou feminilidade e ritos), racional (benefícios, funcionalidades, características, relações causais, estrutura e ordem), visionária (distorções criativas, ilusões e visão ideal) e temáticas emergentes (sugestões, complementações sobre o tema).

As fases seguintes caracterizam a atribuição de Valores de Ordem (VO) e de Frequência (VF) em relação à aparição dos atributos gerada na análise das entrevistas. Deste modo, valores maiores correspondem à imagem central, enquanto valores mais baixos localizam-se na periferia da imagem. Conforme De Toni e Shuler, os Valores de Ordem são calculados da seguinte forma:

Quando um atributo é citado em primeiro lugar, recebe um valor 5; quando citado em segundo lugar, valor 4; quando citado em terceiro lugar, valor 3; se citado em quarto lugar, valor $2 \mathrm{e}$, finalmente, em quinto lugar, recebe o valor 1 . Depois do quinto lugar de aparição, os atributos não recebem mais Valor de Ordem (VO), somente Valor de Frequência (VF) (2015, p.167).

A partir disso, percebe-se que os VO se referem à posição do atributo na mente de um respondente, individualmente, portanto, mas caso seja repetido várias vezes, significa que este atributo é fortemente ligado ao objeto de análise. Já os Valores de Frequência (VF) são identificados pelo número de vezes que o atributo foi citado pelos sujeitos. Assim, para cada citação de um indivíduo, atribui-se o VF = 1 , sendo seu total correspondente ao somatório de todos os sujeitos da pesquisa que o citaram. Por fim, os Valores Totais (VT) são obtidos pelo somatório simples entre VO e VF e compõem a imagem central do produto estudado.

Com base nesses procedimentos, deve-se atribuir as zonas de proximidade dos atributos em relação ao termo indutor "Editora UFSM". Para tal, utiliza-se o VT e aplica-se o procedimento de divisão em quartis. $\mathrm{O}$ intervalo gerado pelo quarto quartil corresponde aos valores mais altos e acolhe os atributos considerados como pertinentes à Imagem Central; o terceiro quartil corresponde ao intervalo de segundo valor mais alto, e é considerado como Primeira Periferia da Imagem Intermediária; o segundo quartil corresponde ao intervalo de terceiro valor mais alto e é denominado Segunda Periferia; e o primeiro quartil, correspondente ao intervalo de valores menores, é chamado simplesmente de Margem da Imagem. Posteriormente, é o momento de realizar a configuração de agrupamentos dos atributos de acordo com suas dimensões de imagem. Deste modo, os quatro atributos encontrados e manifestados pelos respondentes são listados e, em seguida, classificados em suas respectivas dimensões, pelo julgamento do próprio pesquisador, baseado nas dimensões e seus respectivos sinalizadores. 
Para as questões emergentes, as quais não fazem parte do MCI, o procedimento de análise foi realizado a partir do conteúdo latente (ROSSI; RESSALVO; JOÃO, 2014). Neste sentido, diante do conteúdo latente, ou seja, obtido mediante interpretação e identificação de aspectos de relação, foi utilizada a análise do conteúdo das entrevistas de forma convencional e direta. Na convencional, para obtenção de categorias a partir dos dados, o que permeia a pesquisa exploratória. Já a direta, por categorias previamente elencadas na teoria, caracteriza o aspecto descritivo. A seção 4 apresenta a análise e interpretação dos resultados.

\section{RESULTADO}

\subsection{Caracterização dos respondentes da pesquisa}

Em relação à caracterização dos sujeitos da pesquisa, houve um equilíbrio quanto ao gênero, tendo em vista que se trata de cinco pessoas do feminino e cinco do masculino. A idade média dos participantes é de 54 anos. No que tange ao perfil acadêmico, evidenciou-se que cinco respondentes pertencem às Ciências Humanas, sendo as áreas do doutorado voltadas à Antropologia Social; História, Geografia e História da Arte; Psicologia Social; Sociologia; e Filosofia. Destes, três têm pós-doutorado e apenas um entrevistado é bolsista de produtividade nível 2 do Conselho Nacional de Desenvolvimento Científico e Tecnológico (CNPQ). Dos demais, dois estão vinculados às Ciências Biológicas com doutorado em Fisiologia, sendo um pós-doutor e bolsista de produtividade do CNPQ, nível 1A. Os demais têm características únicas: um é pós-doutor e possui vínculo nas Ciências Agrárias e nível de produtividade 1D; o segundo pertence às Ciências Sociais Aplicadas, doutorado em Comunicação e bolsa de produtividade nível 2; e o terceiro, vinculado à Linguística, Letras e Artes, sendo doutor em Arte e Cultura Visual. Em relação ao tempo de vínculo com a UFSM, a média dos entrevistados é de 20 anos, sendo que o entrevistado com menor tempo de vínculo possui 4 anos na instituição e o com maior tempo, 43 anos.

No que se refere ao perfil das publicações em livros dos sujeitos, observou-se que o entrevistado que mais tem livros publicados possui 15 livros, sendo também o que tem mais livros autorais (6). Já em relação aos livros organizados, dois possuem 8 organizações. Em relação às publicações na Editora UFSM, o entrevistado que mais possui livros publicados por esta tem 6 obras. Referente a livros publicados em outras editoras, quem mais se sobressaiu possui 14 obras. A próxima subseção se propõe a identificar os atributos e delimitação das zonas da imagem da Editora UFSM.

\subsection{Identificação dos atributos e delimitação das zonas da imagem da Editora UFSM}

Com base na análise das entrevistas realizadas, foram relacionados os atributos de acordo com a frequência de citações (VF) pelos sujeitos. Verificaram-se 62 atributos diferentes expostos pelos entrevistados. Observou-se que metade dos atributos levantados pelas entrevistas foi até três vezes mencionado, o que infere que sejam opiniões mais pontuais e particulares de alguns autores entrevistados.

Com relação à sua proximidade com o termo indutor (Editora UFSM), os quartis foram elaborados a partir do somatório final de Valores Totais (VT) encontrados. Considerou-se como escala os valores entre 2 e 816 (onde 2 é o menor VT e 816 é o somatório de todos os VTs), correspondentes ao total de evidências de frequência e ordem somadas. Nesta escala, foram criados quatro intervalos (816/4): imagem central (entre 816 e 613); primeira periferia (entre 612 e 409); segunda periferia (entre 408 e 205); e margem (entre 204 e 2). Na Tabela 1, estão elencados os atributos da imagem central e seus respectivos 
valores totais (VT) - obtidos pela soma dos valores de ordem (VO) e dos valores de frequência (VF).

Tabela 1 - Atributos da Imagem Central da Editora UFSM por valores totais

\begin{tabular}{lclccc}
\hline Dimensão & Posição & \multicolumn{1}{c}{ Atributo } & VO & VF & VT \\
\hline Racional & $1^{\circ}$ & $\begin{array}{l}\text { Meio para publicação das pesquisas, disseminação do } \\
\text { conhecimento }\end{array}$ & 36 & 10 & 46 \\
\hline Visionário & $2^{\circ}$ & $\begin{array}{l}\text { Ampliação, qualificação, traduções e abrangência } \\
\text { internacional }\end{array}$ & 35 & 10 & 45 \\
\hline Racional & $3^{\circ}$ & Editoração & 28 & 16 & 44 \\
\hline Afetivo & $4^{\circ}$ & Acolhimento das ideias & 25 & 17 & 42 \\
\hline & Fonte: elaborado pelos autores (2019)
\end{tabular}

A partir da revisão de literatura, foi possível constatar que os atributos que circundam o núcleo, ou seja, aqueles pertencentes à imagem central podem ser caracterizados como os que mais perpassam as ideias do consumidor em relação ao objeto analisado, enquanto as áreas intermediárias ou de margem abarcam elementos mais particularizados pelos sujeitos (ABRIC, 1984). Neste sentido, como se pode observar na Tabela 1, a imagem da Editora UFSM está diretamente relacionada a atributos de dimensão racional, como um meio para publicação das pesquisas, disseminação do conhecimento e aos aspectos de qualidade da editoração dos livros; assim como de dimensão visionária, a qual evidencia a intenção de que a Editora seja ampliada, qualifique-se, assuma as traduções para o seu escopo editorial e ganhe abrangência internacional e de ordem afetiva, relacionado ao acolhimento das ideias. A partir disso, evidencia-se que, de modo geral, os autores entrevistados apreciam o trabalho desempenhado pela Editora UFSM, mas deseja que ela se expanda cada vez mais, o que contribui com o espaço que suas obras podem ganhar no cenário de editorações.

Pela mesma lógica, evidenciaram-se os atributos da primeira periferia, suas dimensões e seus respectivos valores totais (VT). Assim, na primeira periferia da imagem da Editora UFSM, encontraram-se alguns elementos de dimensão visionária como continuidade dos trabalhos já executados, inserção de auxílio editorial para figuras e maior investimento no formato e-book. Na dimensão racional, foram atribuídos elogios referentes à comunicação e ao aspecto de a Editora UFSM aceitar pesquisas que não teriam espaço em editoras comerciais, devido às suas especificidades. Já a categoria afetiva evidenciou a estima que os autores entrevistados têm pela Editora, bem como a crítica de que deveria haver um amadurecimento nas questões administrativas, com relação ao acolhimento de autores e comprometimento prévio com originais, impessoalidade, seriedade e profissionalismo. Além disso, a dimensão emocional mostrou que o senso de pertença e vínculo com a UFSM são atributos vinculados à imagem da Editora UFSM.

Em relação aos atributos da segunda periferia, observou-se que estes são majoritariamente de dimensão racional, dos quais alguns evidenciam qualidade, como ter um crivo e rigor editorial, conseguir realizar a distribuição dos livros, possuir uma boa revisão, entre outros; enquanto alguns aspectos são negativos e estão atrelados ao período pré-publicação, os quais enfatizam a morosidade nos processos, bem como a burocracia documental necessária para submissão do original ao Conselho Editorial. Já nas dimensões afetiva e emocional preponderaram elogios à equipe, os quais atribuíram características como cooperação e sintonia, bom atendimento, acolhimento, afeto, receptividade e cortesia.

No que tange aos atributos marginais referentes à imagem da Editora UFSM, evidenciou-se que aqueles de dimensão racional são preponderantes, mais uma vez, e perpassam 26 dos 36 que totalizam o quartil da margem. Dentre esses, pode-se destacar como positivos a qualidade do conteúdo das publicações e a possibilidade de autores externos publicarem na Editora; em contrapartida, alguns aspectos 
negativos destacados são dificuldade de comercialização, circulação e inserção no mercado de alguns títulos do catálogo, extravio de documentos por parte da secretaria e insatisfação nos pareceres emitidos pelo Conselho Editorial. Ademais, observa-se a preocupação para que a Editora UFSM não perca o foco como editora - sua missão - e também a respeito da dificuldade em prospectar bons originais.

Complementar a isso, perpassam as dimensões afetivas que mostram o receio quanto ao estabelecimento de relações predatórias dos autores com a Editora. Na dimensão visionária, observa-se a visão de que a Editora deveria estabelecer uma política agressiva de indução de autores e obras, ampliação e capacitação da equipe, melhoria na agilidade dos processos e a publicação das melhores teses, a exemplo das universidades de Cambridge e Oxford. Destaca-se que, na zona de margem, não houve atributos de ordem emocional. Na sequência, apresenta-se a predominância de cada dimensão de imagem da Editora UFSM proposta pelo MCI.

\subsection{Dimensões da imagem da Editora UFSM}

A partir da análise das entrevistas, os atributos encontrados na pesquisa foram classificados nas dimensões afetiva, emocional, racional e visionária. Desse modo, a categorização dos atributos que compõem a imagem da Editora UFSM, de acordo com os autores sujeitos da pesquisa, mostrou que $52,21 \%$ estão atrelados à dimensão racional, 23,28\% vinculados ao aspecto visionário, 16,18\% a questões afetivas e $8,33 \%$ a atributos emocionais. Neste sentido, questões relativas à dimensão racional mostraram ser mais representativas dentre os atributos relacionados à Editora UFSM, seguida pelos aspectos visionários, os quais remetem àquilo que os autores desejam para a Editora. Segundo a Teoria do Núcleo Central, constata-se que tais atributos sejam os mais representativos do entendimento comum para os autores entrevistados sobre a Editora UFSM. Convém destacar que, dos quatro atributos que se encontram na imagem central, dois estão atrelados à dimensão racional (meio para publicação das pesquisas, disseminação do conhecimento e editoração), o que sugere consistência com os resultados (SCHULER; DE TONI, 2015).

Em relação à composição de cada uma das dimensões, a dimensão racional foi a mais saliente, representado 52,21\% do VT. Isso demonstra que a Editora, para os sujeitos da pesquisa, é caracterizada como um órgão reconhecido sumariamente por suas funcionalidades, características e benefícios. Os atributos que mais se destacaram nesta dimensão foram ser um meio para publicação das pesquisas e disseminação do conhecimento (5,64\%), a qualidade empregada na editoração dos livros $(5,39 \%)$, a melhoria da comunicação da Editora (4,17\%), ser um meio para a divulgação de pesquisas que não teriam espaço em editoras comerciais, devido às suas especificidades $(2,57 \%)$ e ser uma editora boa e séria $(2,45 \%)$.

A segunda dimensão mais representativa foi a visionária $(23,28 \%)$. Dentre os principais atributos que os autores pesquisados almejam para o futuro da Editora UFSM, consta que ela qualifique seus trabalhos, bem como seja ampliada mediante adoção de linhas de traduções e abrangência internacional $(5,51 \%)$, que dê continuidade aos trabalhos já executados $(4,66 \%)$, que a editoração auxilie no trabalho dos autores com figuras $(3,55 \%)$, que invista mais no formato e-book $(2,57 \%)$ e que estude a possibilidade de alteração na política de direito autoral para retorno financeiro aos autores $(1,47 \%)$.

A terceira dimensão mais citada foi a afetiva $(16,18 \%)$, a qual remete que os atributos manifestados nesta natureza ensejam o reconhecimento, ao respeito e à valorização (SCHULER; DE TONI, 2015) pela Editora UFSM. Neste sentido, de forma positiva, obtiveram os atributos que expõem o acolhimento das ideias dos autores $(5,15 \%)$, a estima pela Editora $(3,92 \%)$ e o acolhimento, afeto, receptividade e cortesia da equipe $(1,96 \%)$. Em contrapartida, obteve-se um alerta para um 
amadurecimento de questões administrativas $(2,57 \%)$.

Por fim, a quarta dimensão, a qual obteve menor representação na imagem dos respondentes, foi a emocional $(8,33 \%)$. Esta percorre sinalizadores que indicam o desejo de pertencer, as impressões de prazer no contato, dentre outros. Assim, destaca-se o sentimento de pertença e vínculo com a UFSM $(2,45 \%)$, a percepção de cooperação e sintonia da equipe $(2,33 \%)$ e o bom atendimento prestado $(2,33 \%)$.

A partir disso, pode-se considerar que, dentre os aspectos relevantes positivos relacionados à Editora que merecem ser destacados, encontram-se qualidade editorial; acolhimento de ideias; boa comunicação com o público; realização com eficiência e eficácia da distribuição dos livros; adoção de um processo editorial com acuidade e qualidade, acolhida aos autores de modo afetuoso, receptivo e cortês. Por outro lado, surgem aspirações, receios e críticas relatadas pelos entrevistados que merecem destaque: ampliação e qualificação da editora com inserção de traduções e abrangência internacional; processos prépublicação demasiadamente morosos; acuidade para que a editora não perca seu foco instituído em sua missão como editora que publica livros; dificuldade da editora em prospectar bons originais e insatisfação com os pareceres emitidos pelo Conselho Editorial.

Ademais, dentre os atributos identificados como questões de melhoria imediata e/ou que merecem ser discutidos e revistos pelo gestor, estão auxílio editorial de figuras dos originais aprovados pelo Conselho Editorial; amadurecimento de questões administrativas; alteração da política de direito autoral por retorno financeiro ao invés de percentual em livros; inserção de uma política agressiva de indução com características pré-estabelecidas (refere-se à prospecção de obras por parte da Editora); busca por alternativas que visem a dificuldade de comercialização e circulação de alguns títulos, bem como inserção em alguns mercados; maior acuidade na revisão de algumas obras; busca por maior organização por parte da secretaria para evitar o extravio de documentos e a atenção para que a Editora não seja alvo de relações predatórias por parte de autores que visam qualificar seus currículos, não tomando o devido cuidado com a qualidade de seus originais submetidos à publicação.

\section{CONSIDERAÇÕES FINAIS}

Este estudo objetivou identificar como se configura a imagem da Editora UFSM na percepção do segmento dos autores docentes vinculados à UFSM. Constatou-se o levantamento de 62 atributos, sendo que metade foi mencionado até três vezes, inferindo serem opiniões mais pontuais dentre os entrevistados. De modo geral, pode-se considerar que as principais imagens vinculadas à Editora UFSM remetem ou a sua finalidade, ou abordam lembranças positivas.

No que tange à composição da imagem, a categoria racional foi a que mais representativa, com 52,21\%, demonstrando que a Editora UFSM é caracterizada principalmente, para os sujeitos da pesquisa, pelas suas funcionalidades, características e benefícios. A segunda dimensão mais representativa foi a visionária, a qual remete àquilo que os autores desejam para a editora, representando $23,28 \%$. Neste sentido, os atributos que se sobressaíram referiam-se à continuidade aos trabalhos já executados, auxílio editorial no trabalho dos autores com figuras e maiores investimentos no formato e-book. As dimensões afetiva e emocional tiveram representatividade de $16,18 \%$ e $8,33 \%$, respectivamente. Destas, dentre os atributos mais representativos, destacam-se a estima pela Editora, o acolhimento, o afeto, a receptividade e a cortesia da equipe, o sentimento de pertença e vínculo com a UFSM, a percepção de cooperação e sintonia da equipe e o bom atendimento prestado. Em contrapartida, obteve-se o alerta para um amadurecimento de questões administrativas. Por fim, também foram destacadas questões complementares em relação à publicação de livros. 
O estudo demonstrou que a Editora UFSM assume uma imagem positiva para os autores docentes pesquisados, no entanto, há algumas questões pontuais que merecem ser revistas pela gestão para que atendam melhor às expectativas dos autores. É preciso destacar que algumas proposições são dependentes de interesses políticos e/ou envolvem recursos para que sejam executadas. Ainda assim, faz-se necessária uma análise criteriosa dos atributos propostos pelos autores, tendo em vista a necessidade de manutenção das editoras universitárias num cenário nacional de restrições orçamentárias às universidades e de forte apelo à publicação de artigos em periódicos, em que as editoras precisam validar seus propósitos e conquistar obras relevantes para o desenvolvimento e contribuição para a ciência, reiterando sempre seu papel social para além das fronteiras da academia.

No que se refere às limitações do estudo, destaca-se o curto período de duração da pesquisa, o que conteve a quantidade de pessoas que poderiam ser ouvidas, assim como a restrição dada aos sujeitos, apenas autores docentes, quando outras categorias de autores com percepções e interesses distintos poderiam também ser abrangidas. Neste sentido, como sugestão para estudos futuros, salienta-se a continuidade da proposta iniciada neste trabalho, com o objetivo de compreender a visão das demais categorias de autores.

\section{REFERÊNCIAS}

ABRIC, J. C. A theoretical and experimental approach to the study of social representations in a situation of interaction. In: FARR, R. M.; MOSCOVICI, S. (eds.). Social representations. Cambridge: Cambridge University Press, 1984.

BARICH, H.; KOTLER, P. A framework for marketing image management. Sloan Management Review, Cambridge, v. 32, n. 2, p. 94-104, 1991.

BORGES-ANDRADE, J. E.; PILATI, R. Validação de uma medida de percepção de imagens organizacionais. Revista de Administração Contemporânea, v. 4, n. 1, Curitiba, jan/abr, 2000.

CASTRO, H. C.et al. Percepções sobre o Programa Bolsa Família na sociedade brasileira. Opinião Pública, Campinas, v. 15, n. 2, p. 333-355, nov. 2009.

CHAPMAN, J. A.; FERFOLJA, T. Fatal flaws: the acquisition of imperfect mental models and their use in hazardous situations. Journal of Intellectual Capital, Bradford, v. 2, n. 4, 2001.

DE TONI, D. Administração da imagem de produtos: desenvolvendo um instrumento para a configuração da imagem de produto. Tese (doutorado). Universidade Federal do Rio Grande do Sul, Porto Alegre, 2005.

DE TONI, D.et al. A imagem do comércio varejista e a satisfação dos consumidores: um estudo exploratório ambientado em uma cidade da serra gaúcha. BASE - Revista de Administração e Contabilidade da Unisinos, v. 8, n. 1, jan./mar. 2011.

FARR, R. M. Representações sociais: a teoria e sua história. In: GUARESCHI, P. A.; OVCHELOVITCH, S. (Org.). Textos em representações sociais. 3 ed. Petrópolis: Vozes, 1995.

FOX, K. F. A.; KOTLER, P. Marketing estratégico para instituições educacionais. São Paulo: Atlas, 1994.

JOLY, M. Introdução à análise da imagem. 14 ed. Campinas: Papirus, 2012. 
JOVCHELOVITCH, S. Representações sociais: para uma fenomenologia dos saberes sociais. Psicologia e Sociedade, v. 10, p. 54-68, jan./jun. 1998.

KOTLER, P.; KELLER, K. L. Administração de Marketing. 12 ed. São Paulo: Pearson Prentice Hall, 2006.

MARTINEZ, E; CHERNATONY, L. The effect of brand extension strategies upon brand image. Journal of Consumer Maketing, v. 1, n. 1, p.39-50, 2004.

MOSCOVICI, S. A representação social da psicanálise. Tradução de Cabral. Rio de Janeiro: Zahar, 1978.

NOLETO FILHO, P. A. Mídia e política na imagem do Congresso [recurso eletrônico]. Brasília:

Câmara dos Deputados, Edições Câmara, 2014.

REYNOLDS, T. J.; GUTMAN, J. Advertising is image management. Journal of Advertising Research, v. 24, n. 1, p. 27-38, 1984.

ROSSI, G. B; SERRALVO, F. A.; JOÃO, B. N. Análise de Conteúdo. Revista Brasileira de Marketing, v. 13, n. 4, set. 2014.

SANTAELLA, L.; NÖTH, W. Imagem: cognição, semiótica, mídia. 3 ed. São Paulo: Iluminuras, 2001.

SCHULER, M.; DE TONI, D. Gestão da imagem de organizações, marcas e produtos: através do MCI: método de configuração de imagem. São Paulo: Atlas, 2015.

STERN, B.; ZINKHAN, G. M.; JAJU, A. Marketing images: construct definition, measurement issue, and theory development. Marketing Theory, Londres, v. 1, n. 2, p. 201-224, dez. 2001.

VAZ, G. N. Marketing Institucional: o mercado das ideias e imagens. São Paulo: Pioneira, 1995. 